\title{
Predictors of Re-Emerging Tuberculosis: A Review
}

\author{
Rafiq Shajahan1, Parasakthi Navaratnam¹, Ganesh Kasinathan², Amudha Kadirvelu1, \\ Naganathan Pillai ${ }^{1}$ \\ ${ }^{1}$ Monash University Malaysia, Jalan Lagoon Selatan, Bandar Sunway, Malaysia \\ ${ }^{2}$ Department of Medicine, Segamat Hospital, KM 6 Jalan Genuang, Johor, Malaysia \\ Email: ohlookitsrafiq@gmail.com
}

Received 3 March 2016; accepted 17 March 2016; published 22 March 2016

Copyright (C) 2016 by authors and OALib.

This work is licensed under the Creative Commons Attribution International License (CC BY). http://creativecommons.org/licenses/by/4.0/

(c) (i) Open Access

\begin{abstract}
Tuberculosis (TB) is a deadly disease that still remains a global burden despite of world-wide measures to curb the disease. As of 2015, the goals of the WHO STOP TB Strategy (2006-2015) have been met and the new WHO End TB Strategy (2015-2030) has been implemented with aim of eradicating the disease. Following that, further studies have demonstrated that TB is a disease that cannot be controlled purely by anti-tuberculous medication alone. It is widely understood that various factors such as rising income inequality, overcrowding populations, compliance to healthcare and resistance pose great barriers to the eradication of disease. In many developing countries including Malaysia, TB is showing or re-emerging trend in both reported cases and resistance. Various predictors for poor disease outcome have been mentioned in the literature such as demographic factors, socio-economic instability and severe comorbidities amongst the population. Therefore, a prompt review and understanding of the factors at play in the sequestration of TB cases in high risk groups may better inform preventative measures in the future.
\end{abstract}

\section{Keywords}

Tuberculosis, Risk Factors, Predictors, Socio-Economic, Comorbidities

Subject Areas: Internal Medicine

\section{Introduction}

\subsection{Overview of Tuberculosis}

Tuberculosis (TB) is a disease that has been affecting man since antiquity with some of the earliest known human isolates dating back some 4000 years ago [1]. It has since then proved to be a deadly disease, contributing to 3 million deaths annually according to recent statistics [2] [3]. Tuberculosis is widely understood to be a

How to cite this paper: Shajahan, R., Navaratnam, P., Kasinathan, G., Kadirvelu, A. and Pillai, N. (2016) Predictors of Re-Emerging Tuberculosis: A Review. Open Access Library Journal, 3: e2520. http://dx.doi.org/10.4236/oalib.1102520 
chronic disease caused by Mycobacterium tuberculosis, a rod-shaped, non-spore-forming, aerobic bacterium [3]. Once inhaled, the bacteria containing air droplets that bypass the mucocilliary system will invade the alveolus and will be engulfed by macrophages, specifically its cellular phagosome [2] [4]. Furthermore, opsonisation by the complement protein C3 helps increase the recognition of the organism to the macrophage [4]. If a person has a functioning cell-mediated immune system, an accumulation of activated $\mathrm{T}$ lymphocytes and macrophages called a granuloma will form in an attempt to limit the replication and spread of the M. tuberculosis organism [5]. This may result in a period of latency in infection during which he/she does not express the symptoms of TB. However in some instances especially, if the infected person has reduced immunity, the granuloma may cavitate, resulting in active TB. Hence, whether an infected person has active TB is determined by the dynamic equilibrium between host immune system integrity and the pathogens persistence in the body [4] [5].

Active TB infection presents predominantly with respiratory symptoms and signs such as cough, haemoptysis chest pain, respiratory insufficiency and systemic symptoms like weakness, fever, weight loss and night sweats [1] [3] [5]. In approximately $15 \%$ of patients, there can be extra pulmonary TB in various sites such as the pleura, liver, lymph nodes, spleen, the musculoskeletal system, heart, brain, meninges, genital-urinary system, peritoneum and skin [2] [6]. These extra pulmonary presentations often require longer and more intensive drug regimen [7]. Diagnosis of TB can be made via multiple ways including the Tuberculin Skin Test (TST), sputum smear microbiological examinations and cultures and susceptibility testing along with newer techniques including the Nucleic Acid Amplification (NAA) technique such as Polymerase Chain Reaction (PCR) and the Interferon-gamma release assays [2] [3] [8]. Chemotherapy for non-resistant TB involves a primary intensive regimen of isoniazid, rifampicin, pyrazinamide and streptomycin (or ethambutol) for 2 months followed by a 4month maintenance regiment of isoniazid and rifampicin in fixed dose combinations (FDC) [2] [3]. In addition, dosing frequency for new patients with pulmonary TB should follow daily administrations in the intensive phase followed by 3 times weekly in the maintenance/continuation phase [7] [9]. In Malaysia, some 75\% of patients are on this regimen while the rest are on treatment duration longer than 6 months and with different combinations due to either resistance, extra-pulmonary TB or treatment failures [10]. For previously treated TB cases, the WHO recommends the 2HRZE/1HRZE/5HRE regimen with HRE being strongly recommended in those with Isoniazidresistance [9]. MDR-TB poses a significant challenge to treatment and in countries where routine molecular based drug susceptibility testing is not routine, an empirical regimen of Moxifloxacin, Amikacin, oral Pyrazinamide, Ethionamide and Cycloserine can be used [11]. Extra-pulmonary disease should be treated with the same regimens as their pulmonary counterparts but with differing lengths of treatment. The WHO recommends 9 - 12 months for TB meningitis due to its high risk of disability and mortality, 9 months for bone and joints due to difficulty in establishing a treatment response. Adjuvant corticosteroids are mandated in those with TB meningitis and pericarditis with streptomycin replacing Ethambutol in TB meningitis [9]. Patients with nonMDR-TB have a $90 \%$ cure rate when treated with 4 drugs over 6 months and those with MDR-TB have around $60 \%$ - 75\% cure rates with a 5-drug regimen for a minimum of 20 months [12]. Today, revolutionary treatment strives to institute drugs with better bacteriostatic and bactericidal actions along with frequent follow up for side effects and smear clearance of $M$. tuberculosis via the continuation of the highly successful Directly Observed Treatment, Short-Course (DOTS) programme [1] [8].

\subsection{Global Epidemiology of TB}

More than half a century after the introduction of chemotherapy, Tuberculosis (TB) still remains a force to be reckoned with. It is still a major cause for mortality and morbidity with the World Health Organisation (WHO) estimating that one-third of the population of the world is infected with Mycobacterium tuberculosis. Only a small proportion of $8 \%-10 \%$ of them present with the active disease [7]. There has been progress in the control of TB [13]. Following the implementation of the WHO STOP TB Strategy (2006-2015), the global incidence of TB has dropped at an average rate of 1.5\% from year 2000-2014 [7]. The mortality rate of TB in 2015 is half the rate it once was in 1990 and around 43 million lives have been saved thanks to improved diagnosis, early detection and improved management [7] [14]. These statistics indicate that the world has achieved the Millennium Development Goal (MDG) of reversing the incidence of TB by 2015 [7]. However, much remains to be done. There were 9.6 million new cases of TB and 1.5 million lives lost in the year 2014 [7] [15]. TB has infected approximately 1 million children in the year 2014 alone and remains the number 1 killer in HIV infected individuals. One third of deaths amongst HIV positive persons is attributable to TB [7] [10] [16]. Furthermore, approx- 
imately 480,000 people developed Multi-drug Resistant TB (MDR-TB) in 2014 along with the emergence of Extensively Drug Resistant Tuberculosis (XDR-TB) in some countries, including Malaysia [7] [16] [17]. XDR-TB is diagnosed when an active TB patient is resistance to not only Rifampicin and Isoniazid as with MDR-TB, but also any Fluoroquinolone and at minimum one of the injectable second-line drugs (i.e. amikacin, capreomycin or kanamycin) [1] [7] [17] [18]. To eradicate TB, the WHO adopted the new WHO End TB Strategy (2015-2030) that serves to reduce the number of TB deaths by $90 \%$ and to reduce incidences by $80 \%$ by the year 2030 [7].

\subsection{Epidemiology and Control of Tuberculosis in Malaysia}

\subsubsection{Epidemiology of Tuberculosis in Malaysia}

In Malaysia, 24,711 new and relapsed cases of TB were diagnosed in the year 2014 [20]. There has been an overall increasing trend in notified cases (Figure 1) with a steady rise from 50/100,000 population in 1990 to 110/100,000 population in 2014 (Global average in 2014 was 133/100,000) [7] [20]. National TB statistics indicate that the incidence of TB cases has increased from 15,000 in 2005 to 19,251 in 2011 (Figure 1) [14] [19]. Furthermore, Selangor, a state formerly known for its low incidence in TB, had notified 43.1 cases/100,000 population in the year 2000 as compared to 31.2 cases/100,000 in the year 1995 [21]. Today, Selangor has the second highest state in terms notified cases of TB with approximately 3250 cases from years 2005-2011 [6].

Besides that, the rates of default to treatment and death due to TB for years 2010-2013 remained unimproved at $4 \%$ and $9 \%$ respectively (Figure 2). The cure rates (\%) and mortality rates of TB patients in Malaysia (per 100,000 population) in the year 2013 were 77\% (Figure 2) and 5.4 (Figure 3) which were not close to the WHO

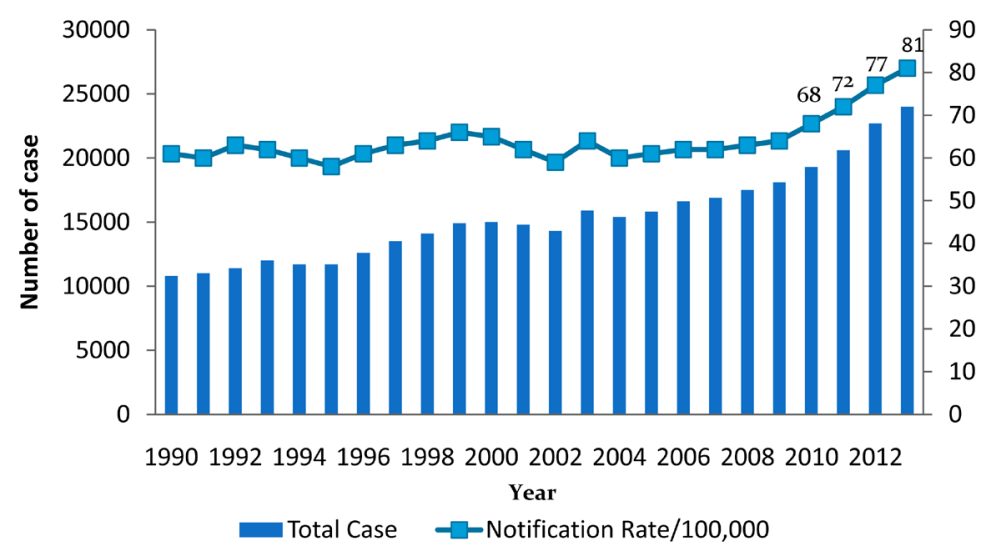

Figure 1. Incidence (notification of new and relapsed cases) rate of TB (per 100,000) Malaysia (1990-2013): [19].

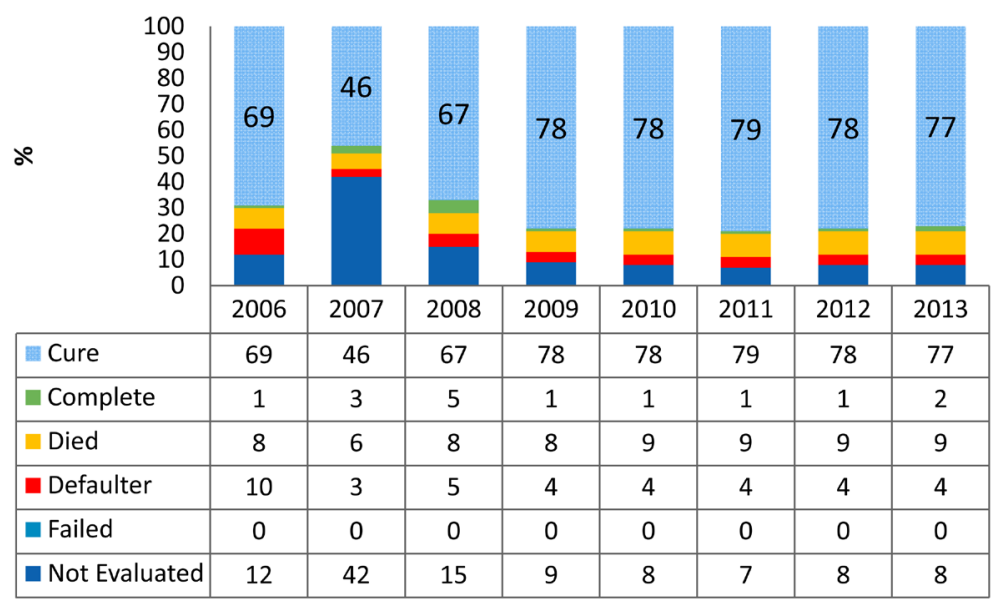

Figure 2. Treatment outcome of new smear positive cases (Cohort 2006-2013) [19]. 


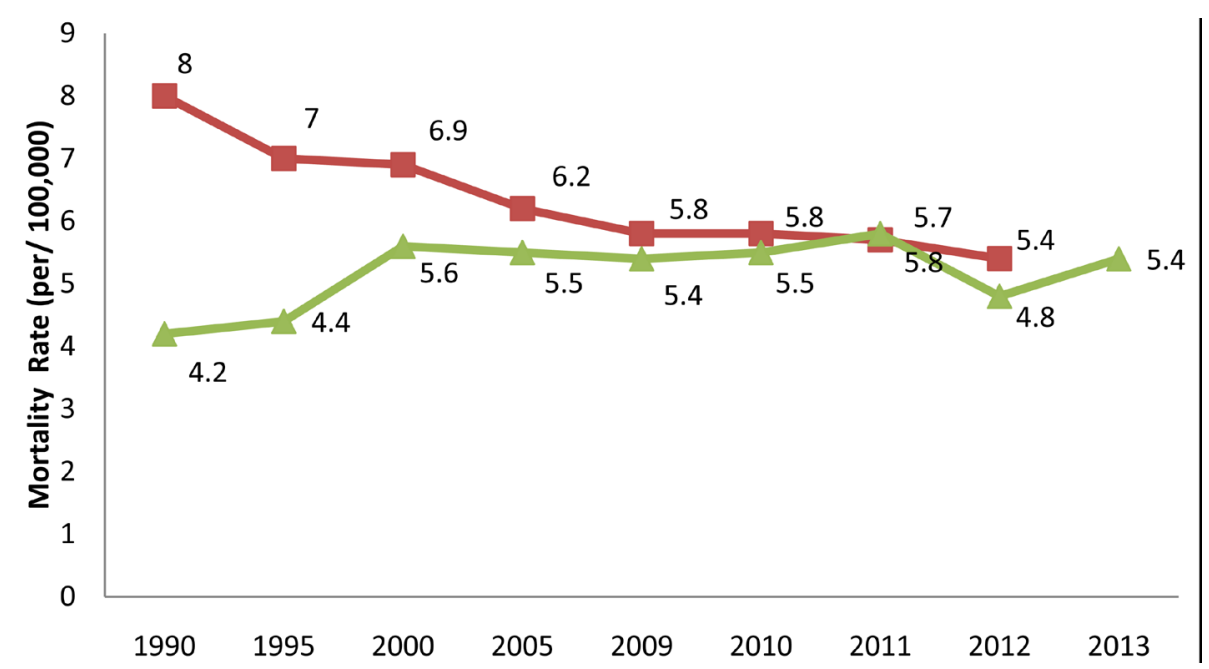

Figure 3. TB Mortality rate in Malaysia (1990-2013) (Red line = WHO estimated mortality excluding TB/HIV mortality; Green line = Malaysia reported TB Mortality rate) [19].

targets of $85 \%$ and 3 respectively with trends showing no improvement as well. In fact, Malaysia recorded 33 deaths related to TB per week in the year 2013 [19]. On the whole, statistics show that Malaysia is seeing a resurgence in the TB epidemic despite great efforts at a public health level. The reason for such worrying figures may be associated with Malaysia still not tackling the known socio-demographic, economic and comorbid factors that are indicated in the STOP TB Strategy of 2006 [19].

Further investigation of Malaysian TB statistics has indicated some emerging trends. It is observed that the majority age group for TB in Malaysia is 21 - 60 years of age (constituting $69.5 \%$ of cases) with $2.7 \%$ of TB cases being under the $\leq 14$ year age group while $12.3 \%$ were over the age of 65 years [14]. There seems to be a slight male predominance (65\%) [22]. In the year 2014, 92.2\% of TB cases were Malaysian citizens and 7.8\% were foreigners [19]. Furthermore, smear rates among new pulmonary TB (PTB) was at 72\% [14].

The rates of Multi-drug resistant TB (MDR-TB) had risen from 0.3\% in 2005 to $1.33 \%$ in 2011 in all AFB cultures that were tested for MDR-TB (Figure 4) [6]. The treatment success rate for MDR-TB was 28\% in the year 2011, which is well below the $80 \%$ target set by WHO (Figure 5). Some of the states that recorded the highest incidence of notified TB cases in decreasing order were Sabah, Selangor, Sarawak and Johor with numbers ranging from more than 3,500 new cases to less than 2000 [14] [20]. Among the states in Malaysia, only Sabah had been able to achieve the higher than 85\% cure rate in the year 2014 (Figure 6).

The data shown in the following figures were presented during the Ninth Technical Advisory Group and National TB Programme Managers meeting for TB control in the Western Pacific Region in the Philippines on December 2014. Evidenced from the data above, there seems to be a worsening trend or re-emergence of various aspects of Tuberculosis in Malaysia, namely the rising number of notified cases over time, increasing TB mortalities, failure to meet target cure rates by states and country and failure to meet treatment outcomes of MDR-TB in Malaysia [19]. Some of the Challenges that Malaysia has to overcome in view of the resurgence of Tuberculosis are [10] [19]:

1) Increasing prevalence TB cases, specifically of sputum negative and relapses.

2) Locals have a high burden of comorbidity and risk factors such as diabetes, HIV, smoking and alcoholism.

3) The rise of more international travel and migrant populations in Malaysia from countries that have TB epidemics as a reported $10 \%$ of TB notified cases come from these groups individuals.

4) Failure to meet WHO target in treatment and cures.

5) Failure to meet global targets in MDR-TB treatment.

There were also a few difficulties noted when prevention of spread of TB comes to attention. Nissapatorn and Lim have demonstrated that the elderly population and those abusing drugs intravenously in Malaysia were implicated in the re-emergence of TB [23]. This could be attributed to higher likelihood of significant comorbidities such as HIV and lowered immune system, within this patient group [24]. Non-compliance, a well-known risk factor for resistance, is more likely to occur amongst the immigrant population in Malaysia as compared to 


\begin{tabular}{|c|c|c|c|c|}
\hline Year & $\begin{array}{c}\text { Notified } \\
\text { TB Cases } \\
\text { (All Forms) }\end{array}$ & $\begin{array}{c}\text { Isolates tested for } \\
\text { Drug Sensitivity } \\
\text { Testing (DST) }\end{array}$ & $\begin{array}{c}\text { MDR } \\
\text { Cases }\end{array}$ & $\begin{array}{c}\text { \% MDR } \\
\text { (By number of } \\
\text { culture positive } \\
\text { tested for DST) }\end{array}$ \\
\hline 2004 & 15429 & 5083 & 13 & 0.3 \\
\hline 2005 & 15875 & 6309 & 17 & 0.3 \\
\hline 2006 & 16665 & 6386 & 42 & 0.7 \\
\hline 2007 & 16918 & 6687 & 41 & 0.6 \\
\hline 2008 & 17506 & 6264 & 56 & 0.9 \\
\hline 2009 & 18102 & 7137 & 55 & 0.8 \\
\hline 2010 & 19337 & 6963 & 51 & 0.7 \\
\hline 2011 & 20666 & 10477 & 141 & 1.3 \\
\hline 2012 & 22710 & 9722 & 74 & 0.8 \\
\hline 2013 & 24071 & 13777 & 124 & 0.9 \\
\hline Okt, 2014 & 17496 & 14607 & 78 & 0.5 \\
\hline
\end{tabular}

Figure 4. MDR-TB rates in Malaysia (2004-2013) [19].

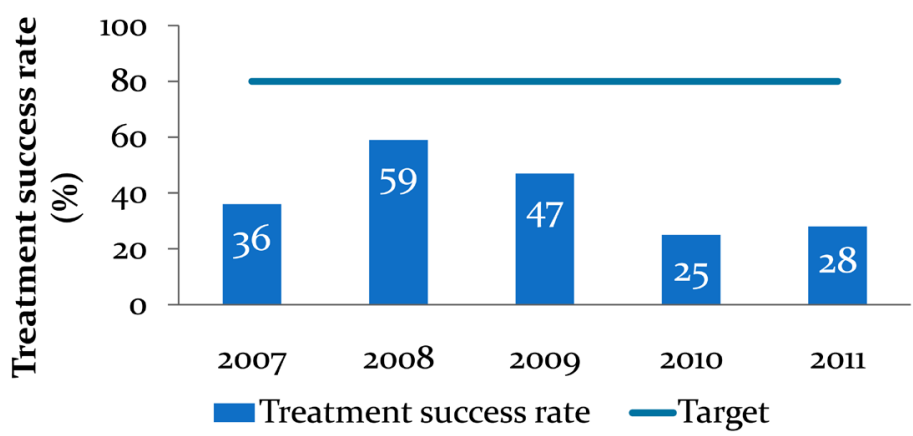

Figure 5. Treatment outcome of MDRTB cases Malaysia (2007-2011) [19].

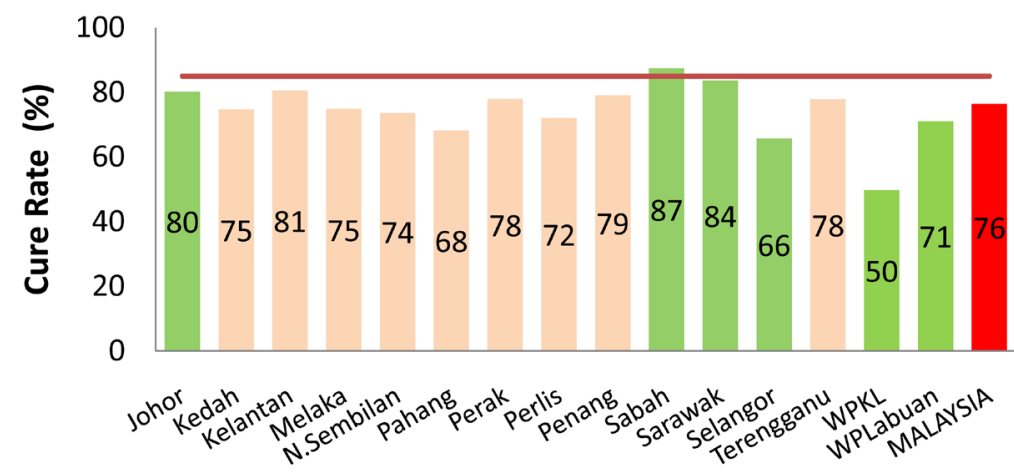

Figure 6. Cure rates from January to September 2014 according to states (Green is the top 6 highest incidence states; Red is the national average) [19].

the locals [23]. Upon greater scrutiny of the data, it was found that this was in part due to them being mostly labourers who were likely not to understand the long term treatment requirements of TB or feared the loss of job security [23]. Employers may help circumnavigate this issues with provisions of medical services and better job security [23]. The same study by Nissapatorn and Lim discovered that only one-third of their study population $(n=425)$ had received the Bacille Calmette Guerin (BCG) vaccine, even though it was part of the national vaccination programme [23]. Following this, research in Malaysia has elucidated that a total of 1021 children had only received their primary vaccination after 1 year of age [25]. Echoing this premise, a proper implementation of the national TB vaccination is has to be an ongoing pursuit with more calls by researchers to develop better and cheaper vaccines than the BCG in countries that have a higher disease burden [26]. The Tuberculin Skin 
Test (TST) which is used as routine screening to detect latent TB is of limited clinical utility in a nation with multi-ethnicities and high BCG coverage such as in Malaysia [23]. Alternatively, Interferon-gamma assays can provide more accuracy in the diagnosis of latent TB but remains expensive and requires specialised training to operate [23]. Malaysia does not have reliable means of monitoring treatment defaulters in TB patients treated in the private medical sector despite some reports claiming that $10 \%-15 \%$ of TB cases nationwide were managed in the private sector and were unlikely to carry out appropriate DOTS therapy [10] [25]. Furthermore, a review of data at a private clinic discerned that TB was identified as the second most detected disease during preemployment screening [24] [27]. In fact, pilot studies had been underway in 3 states to introduce computerised patient recording that will be useful in analysis of treatment results ad programme evaluation [10]. Finally, it has been recommended that greater interagency coordination is required in Malaysia between various institutions (i.e. Prisons, drug rehabilitation centers), the Ministry of Home Affairs and the Ministry of Health to better carry out preventative measures on the logistics of TB screening, education and strategic harm reduction strategies that can help with stigma and awareness of TB amongst high risk groups [25].

\subsubsection{TB Control in Malaysia}

Researchers in 2014 have been able to use geographical data to point out that about $58 \%$ of new incidences of TB in the world occurred in South-East Asia and Western Pacific Region alone [7]. Malaysia, a country that resides in the South-East Asian region, is a country that has been impacted by this condition severely. Historically, there were many sanitoria around the country to confine TB patients and TB was treated surgically before the introduction of chemotherapy in the 1950s [21]. Currently, Malaysia is well known for its focused primary care plans along with its national strategies that holistically address various socio-economic and environmental issues [28]. The Malaysian Government instituted its National TB Control Programme (NTP) in 1961 as TB was then the number 1 cause of mortality at the time [10]. The Malaysian TB programme in influenced by the WHO STOP TB Strategy (2006-2015) and the Millennium Developmental Goals (MDG) which aims to dramatically reduce the global burden of TB via objectives such as universal access to high quality care, reduction in the socio-economic burden associated with TB and to support development and research initiatives [7]. In Malaysia, every state has a board of directors called the State TB Managerial Team that oversees the plans recommended by the WHO [10]. Some of the efforts carried out in Malaysia is the Directly Observed Therapy Short Course (DOTS) programme and a national online registry/helpdesk for TB called MyTB. There are other organisations such as the Malaysian Association for the Prevention of Tuberculosis (MAPTB) that promote events on awareness, helping the locals access adequate treatment and help in carrying out the WHO's Stop TB initiatives in Malaysia [29]. Moreover, the government of Malaysia has been implementing the Health Public Policies in Malaysia and the New Economic Policy (NEP) with the objectives of narrowing the wealth gaps by cultivating socio-economic stability, national development and various health programmes [10] [21]. These collected efforts from many bodies have made great progress as TB is now in the $17^{\text {th }}$ place in terms of causes of mortality in Malaysia [7] [10].

\section{Predictors of Re-Emergence of TB}

The Tuberculosis epidemic has been touted as the "perfect expression of an imperfect civilisation" due to observation that most of the risk factors associated with the high incidence of TB are widely present in developing nations [30]. It is known that action to control TB should come from both effective chemotherapy as well appropriate control of social and economic factors related to its spread [1]. In conjunction with that, Ortblad and Salomon have proposed a "biosocial" approach that amalgamates the use of effective anti-tuberculous medication in tandem with various social improvements and controls on urban planning, occupational health and nutrition [13]. The Commission on Social Determinants of Health (CSDH) has defined "structural determinants" as any factor that brings about social stratification in a community [31]. It is believed that this stratification will in turn lead to a host of inequalities in resources, privileges and determinants of health, especially to the lower socioeconomic population [31]. Hence, with the case of TB, those inequalities of resources and determinants of health includes poor housing, financial insecurities, prevalence of comorbidities and other social and cultural barriers [32]. Alarmingly, in view of the various TB programmes today, many do not adequately address the aforementioned social-demographic, economic and clinical factors that are implied in the propagation of the disease as a result of the social stratification of health [13] [31]. It appears that some of these factors emphasise the delivery of tuberculosis services rather than addressing the key sociocultural factors of the TB epidemic [13] 
[16]. In contrast, there is plenty of evidence demonstrating the effect of these socio-demographic, environmental, and governmental and health factors associated with a higher prevalence and poorer treatment outcomes of TB [22] [33].

\subsection{Key Drivers of the Re-Emergence and Resistance of Tuberculosis: A Review of Studies}

\subsubsection{Evidence from Global Studies}

In 2015, more than $95 \%$ of TB case mortalities occur in low and middle income countries according to WHO estimates [7]. TB mortality will rise from 3 million to 5 million by the year 2050 [1] [18]. The WHO has postulated while reasons such as TB and HIV Co-infection can be held accountable, worsening poverty, increase in world populations, programme inefficiencies, increases in immigration and public indifference to the epidemic will all be contributing factors [18]. A number of studies have been published around the world investigating the socio-demographic, economic and comorbid risk factors as possible predictors of poor outcome and the possible resurgence and resistance of TB to drugs. Retrospective cohort studies done in Rio De Janeiro and Iraq indicated that a number of predictors of poor treatment outcomes such as alternative regimens of anti-tuberculous therapy, low income, poor educational levels, poor financial status, continued smoking, emotional stress, HIV without Anti-retroviral Therapy (ART), lack of bacterial confirmation, Diabetes, and younger age [34] [35]. Studies from South Korea, South Africa and Pakistan further also suggest that factors such as Diabetes, MDR-TB infections, long distance away from health-centre, blue collar workers, prison cell space, duration of incarceration of prisoners and perceptions of health status were markers of poor management outcomes, high incidence of TB epidemics and re-emergence of disease [36]-[38]. Table 1 summarises the findings of these studies.

Table 1. Summarised findings of various TB predictor publications around the world [34]-[38].

Brief description of study

1) Retrospective cohort study in Rio de Janeiro, Brazil of 311 patients from years 2004-2006 (ARR—Adjusted Risk Ratio)

2) Prospective cohort study in 2 tertiary centers in South Korea from years 2005-2012 (limitations represents severe cases of TB as it was done in tertiary centers, not representative of all TB cases)

3) A retrospective cohort study using the Functional Assessment of Chronic Illness Therapy-TB (FACIT-TB) scale to assess health related quality of life in 205 patients in a tertiary center in Iraq. FACIT-TB is a quality of life measure that investigates physical, social, economic and spiritual aspects of someone with or without TB. Administered either face to face interview or self-administered.

4) A cross-sectional prevalence study of 425 randomly chosen participants from 5 prisons in Pakistan. $48 \%$ of those randomly chosen tested positive for latent TB by TST (also called Mantoux test).

1) A cross-sectional survey analysis using selected data collection tools such as

- A Socio-Demographic Questionnaire;

- A Post-Traumatic-Stress Disorder Identification Test

- self-reporting of tobacco use

- self-reporting of perceived health and adherence.

The study investigated the predictors of treatment outcome in 2 groups of patient; those on anti-TB medication $(n=3107)$ and

those on anti-retroviral and anti-TB patients $(\mathrm{N}=757)$ across 14 health facilities in South Africa.

\section{Relevant findings}

Reported that poor predictors of treatment outcome and infection were alternative regimens of SEO (Streptomycin, Ethambutol and Ofloxacin) (ARR: 11.43), Low income (ARR: 11.20), HIV without ART (ARR: 9.64), Lack of bacterial confirmation (ARR: 4.0) Diabetes (ARR: 3.94) younger age (ARR: 3.84) and alcoholism (ARR: 1.76).

- Identified that predictors of End of Study (EOS) outcomes included a diagnosis of Diabetes, presence of MDR-TB, high risk age group, BMI and alcoholism.

- $\quad$ Noted curiously that social stigma of the disease, long distance away from treatment center and blue collar workers also exhibited worse outcomes.

- $\quad$ The study population consisted of almost $30 \%$ illiterate participants and 50\% sole breadwinners. - Poor educational levels, poor financial status, smokers, emotional stress and also psychiatric complications were markers of poorer treatment outcomes and resistance. - It was also noted that a higher baseline FACIT-TB score prior to infection related to a higher health related quality of life with the disease.

- Factors such as age, educational level, smoking status, duration of current incarceration and average accommodation space less than $60 \mathrm{ft}^{2}$ were predictors of poor outcome and high rates of infectivity.

- Significant predictors of poor outcome in both dual therapy and just anti-TB groups were poverty, comorbidities, alcohol misuse and partner who is HIV positive.

- Significant predictors of better outcomes in both dual therapy and just the anti-TB groups that lead to better adherence and less severe disease were to perceive health status as poor, perceive health status as good, HIV negative status, sex partner on anti-retroviral.

- Authors found that a great deal of stigmatisation may deter patients to seek treatment. 


\subsubsection{Evidence from Malaysia}

In 5 different referral hospitals in Malaysia, a case control study was carried out on 105 culture confirmed MDR-TB patients and 209 non MDR-TB patients within the years 2010 to 2014. Factors that were identified with substandard treatment outcomes included previous tuberculosis treatment, co-infection with HIV, being an immigrant and a high Acid Fast Bacilli (AFB) load [17]. Another retrospective cohort study investigated predictors of mortality in TB and HIV co-infected undergoing tuberculosis chemotherapy [39]. This study was done in major hospitals in Selangor and the Klang Valley. The findings included a TB and HIV co-infection rate of $23.3 \%$, which was similar to the rate in the literature with factors such as being Malay, an increase in every $10^{3}$ total WBC per microliter, $\geq 3$ opportunistic infections, not receiving anti-retroviral and low CD4 counts serving as predictors for worse TB status and poor outcomes [39]. Various Malaysian country reports and international country reports on TB identified many socio-economical precipitators of the TB epidemic such as indoor air pollution, malnutrition, diabetes mellitus, tobacco, alcohol, social stigma and social exclusion [19] [33]. These factors invariably promote failure of DOTS therapy, thus contributing to the overall worsening epidemic [10] [16] [33]. Controlling these group level predictive factors for poor disease outcome appear to be an area of possible public health significance [7] [10] [13] [32] [33] [40].

\subsection{Demographic Factors}

\subsubsection{Age, Gender and Ethnicity}

Multiple publications have indicated that children and women are at high risk of TB. A study have shown that once a child is exposed to smear positive or smear negative contacts, the rates of infection are $80 \%$ and $40 \%$ respectively [41]. In 2014, 1 million children under the age of 14 were infected with TB with 140,000 case mortalities [7]. The sole major risk factor for infection with TB in children 2 years of age was household contacts whereas in children after the ages of 5 - 10 years, the community was the source of infection (nursery, schools) [33]. In addition, the age that is at high risk for disease progression following primary exposure was under 2 years and above 10 years of age and the highest risk of mortality was recorded at infancy [41]. This is the reason BCG vaccinations were instituted at birth in many countries including Malaysia. However, statistics show that the majority of TB infections do not occur in children less than 16 years of age as the median age of infection in TB patients in the 1990s were at 49 - 60 years in Caucasian patients and 31 - 43 years in non-Caucasian patients [42].

Women, on the other hand, suffer severely with TB as TB is the third most common cause for mortality and morbidity in women aged 15 - 44 from developing countries (higher than Malaria and AIDS) despite tuberculosis occurring less frequently amongst females [7] [43]. Males are seemingly more likely to express the active disease more frequently as the proportion of female to male tuberculosis case notification internationally stands at $1 / 1.5$ - 2.1. This translates to almost $70 \%$ more smear positive males compared to females being diagnosed and notified annually [44].

The natural history of TB does vary among ethnicities. A study in London showed that immune responses to the TB infection amongst Europeans and Asians were similar but distinctively different from Africans when adjusted for confounders [45]. Authors attributed these differences to variations in genetic factors as opposed to type of strain of TB bacterium as once believed. Interestingly, they have also attributed this to lack of vitamin D, the resultant antimicrobial peptides released in that state and other binding proteins related to it [45]. On the whole, being of a high risk age, gender and ethnic group can increase the probability of poor disease outcomes of TB with some Malaysian authors calling for age, gender and ethnic specific interventions from national TB programmes to address this issue [46]. The racial predisposition for TB in Malaysia is unclear as publications do not show consistency in findings [25]. However, Malays were the majority race expressing TB and HIV co-infection with and the Chinese were the majority race diabetics with TB [25].

\subsubsection{Migrant Population}

The migrant population, especially those originating from nations with high incidence of TB remains an important factor in the re-emergence of Tuberculosis in many countries, including Malaysia. A cross-sectional study performed by Watkins and Plant on the migrant population in various countries discovered that the strongest predictor of the rate of TB amongst the migrant population were high Incidence of active TB in country of birth followed by variables such as socio-economic status of the migrant in the country of residence, gross national 
income of the country of birth and unemployment level of the migrant in the country of residence [40]. Most cases of active TB among this population tend to occur among those who have been exposed to Mycobacterium tuberculosis prior to arrival rather than development in the current country of residence [40]. Individuals from migrant populations are at higher risk of developing Tuberculosis as they are often living in overcrowded spaces, are at an increase vulnerability to HIV, lack of education, lack of access to healthcare, poor health-seeking behaviour and social and cultural barriers [47]. Indigenous or aboriginal populations are also seen to have similar risk factors of the migrant population with the added burden of a high volume of comorbidities such as diabetes, renal impairment and alcohol abuse which can lead reactivation of TB [33].

In Malaysia, the migrant population diagnosed with Tuberculosis rose from 18,000 cases in 2010 to more than 20,000 in the following year with 1600 case fatalities [19]. The percentage of TB cases by nationality (country of origin) in decreasing order are Indonesia (4.9\%), Philippines (4.7\%), Myanmar (1.8\%), Nepal (0.5\%) and Bangladesh (0.5\%) [7] [19]. Furthermore, it was estimated that about 30\% of the total TB cases notified from national referral centres were from foreigners with rates higher in males than females [23]. Foreign workers in Malaysia fared poorly compared to the local population in severity of comorbidities and level of education [19]. Although the rates of default to treatment and transfer outs were greater (20\%) in the foreign population in Malaysia compared locals (1\%), the percentage of new cases and smear negative cases were comparable between the groups [19]. These statistics support the claim that being of a migrant population from a TB endemic country can act as predictor of poor disease outcome.

\subsubsection{Level of Education}

Educational level is also an important factor in the re-emergence of TB. Lower educational status contributes to poor health seeking behaviour, cultural barriers and compliance issues during treatment [33]. Adding to this observation, a 2014 cross sectional study conducted in Bangladesh revealed that patients who had poorer awareness on transmissions, preventions and basic precautions of TB were of those infected with extra pulmonary TB, were females, and were outside the ages 21 - 35, of lower education qualifications and of rural residing individuals [48]. Following that, a study on a population of educated and multilingual immigrant Somalians living in London were seen to be unsure about risk factors, coping with the disease and some of the necessary lifestyle changes but had good understanding on the infectivity of TB and compliance to medication [49].

In Malaysia, education has improved since the 1950's with the rates of individuals participating in primary and secondary education increasing to above $90 \%$ and $80 \%$ respectively in the year 2007 [21] [50]. Literacy rates in those over 15 years of age has also increased from $84.3 \%$ to $92.8 \%$ from years 1989 to 2008 [21] [28] [50]. In addition to that, literacy rates among the urban population outperform the rural population of Malaysia at $95 \%$ compared to $90 \%$ [21]. However, the rates of Orang Asli (Indigenous people in Malaysia) who did not continue secondary school was $36 \%$ [50].

However, good literacy rates do not necessarily equate to the understanding TB. A Knowledge, Attitude and Practice (KAP) study in the year 2012 assessed the awareness and stigma among Universiti Sains Malaysia Students (USM) towards TB and discovered that males knew less than women about TB. The majority of respondents were uncertain of the spread with many claiming that coughing does not spread TB but contaminated food does. There was also a high level of stigma for anyone affected with TB [51]. The authors found the findings troubling as these university students represent a cohort of highly educated individuals and speculated that the results could be worse in less educated individuals [51].

\subsection{Socio-Economic Factors}

\subsubsection{Urban Residence, Living Arrangements, TB Contact and Transmission}

TB outbreaks and epidemics are often observed to be more common in urban areas [33]. This may be due to the fact that urban areas are more likely crowded, facilitating transmission of infected air droplets [32] [52]. Within the social demographics of the urban population, the poor are vulnerable to additional risk factors such as poor nutritional status, crowded living conditions and poor access to healthcare [26]. Other groups of people that live in poverty and in overcrowded areas are those who homeless (OR $=2.9,95 \%$ CI 2.0 to 4.0 ), have a history of incarceration ( $\mathrm{OR}=2.2,95 \%$ CI 1.7 to 2.9), elderly homes (OR $=3.6,95 \%$ CI 1.7 to 7.65$)$ and those in prison (Incidence Rate Ratio = 23.0, IQR 11.7 - 36.1) [53]-[55]. However, living in a rural area may pose problems in terms of access to healthcare and transportation to DOTS therapy. A study done in surrounding communities in 
Kota Kinabalu had demonstrated that non-compliance to DOTS therapy was related to expensive travel fares to health centres, time to travel and stopping treatment when symptoms resolve [56]. On that note, proximity to TB contacts is a significant predictor for development of active disease. It is observed that household contacts are at an obviously higher risk of exposure [33]. Proximity to a TB patient was also reinforced as a predictor of poor disease outcome in a contact study in Gambia where the risk of being Tuberculin Skin Test positive (10 mm or more) included being male, older age group, severe X-ray findings in the index TB patients X-ray and social proximity to the index TB patient [57]. Morrison et al. had conducted a systematic review that provided a break down on the type of TB expressed in the household contacts of a known index patient. The study found that majority of the cases of household contacts expressed latent TB 51.4\% (CI 50.6 - 52.2) followed by bacteriological and clinically diagnosed TB 4.5\% (CI 4.3 - 4.8) and bacteriologically confirmed cases were only 2.3\% (CI 50.6 - 52.2). This finding is in keeping with the knowledge that majority of TB contacts are latent and this provides the basis of contact screening efforts [52] [58]. In summary, factors such as urban residing, crowded living arrangements and proximity to contact are important predictors of re-emergence and persistence of TB in the Malaysia.

\subsubsection{Smoking, Alcohol and Substance Abuse}

More Malaysians smoke according to WHO estimates compared to other TB endemic areas such as Phnom Penh and Cambodia [59]. There are approximately $40 \%$ to 50\% smoking TB patients in Malaysia. It is claimed that more than $20 \%$ of cases of TB are associated with smoking and this has been supported by many studies [7] [52] [60]. Smoking predisposes for mortality in patients with active disease [60]. Some reasons for this findings are dysfunctional mucus secretions, impaired phagocytic function and the emergence of CD4+ Lymphopenia [61]. This results in two fold increased risk of reactivation of latent TB in smokers [25]. Excessive alcohol use has also been implicated as a risk factor as well as an adverse outcome to treatment [52] [59]. According to Malaysian statistics and the WHO, heavy alcohol consumption is seen among rural Indian labourers in Malaysia [50] [59]. Based on a systematic review, it is found that people who drink more than $40 \mathrm{mg}$ of alcohol per day or have an alcohol abuse disorder have a higher risk of active tuberculosis with a RR of 2.94 (CI 1.89 - 4.59) [62]. Related to alcohol abuse, illicit substance abuse is also considered a risk factor for Tuberculosis. A Malaysian retrospective cohort study from the years 1990 to the 2010 identified Intravenous drug use to have a Hazards Ratio of 6.08 (2.4 - 15.39) for developing active TB [63]. A 2014 cross-sectional survey done in a substance abuse treatment centre in Malaysia showed that patients there had a positive Tuberculin Skin Test rate of $86.7 \%$ [64]. Alcoholism, smoking and substance abuse are often means to cope with the accompanying poverty. Inversely, income inequality can often be caused by the abuse of these substances as well [59]. Various studies and publications positively correlate substance abuse along with the HIV epidemics, overcrowding and poverty [55] [59].

\subsubsection{Poverty}

In 1993, the WHO took the bold decision of declaring TB, a world emergency. Ever since then, several countries throughout the years have tried tirelessly to pursue the implementation of economic policies that bring about equity in health as a way of controlling of TB with some success [31] [52]. Lönnroth et al. stated that patients from low socio-economic groups are at risk of being in proximity of a TB contact as they are more likely to live in crowded and poorly ventilated areas [52]. In fact, countries that have a high number of low-socioeconomic citizens, such as developing countries, often have TB as a leading cause of mortality [1]. As of 2015, the WHO states that the funding required for a well-equipped health programme against the global epidemic of TB is approximately at US $\$ 8$ billion, far from the average US $\$ 6$ billion that most countries can afford [7]. Furthermore, funding at the individual level in countries burdened by TB for treating non MDR-TB and MDR-TB in 2014 ranged around US $\$ 100$ - 500 and US $\$ 5000$ - 10,000 respectively [7]. Compounding this problem, the worldwide average household income in 2015 comes in at around US \$9733 which may be insufficient considering TB is making a worrying resurgence in the health scene [65]. In response, many countries have reduced their investments in health which can have effects such as increasing their populations risk of malnutrition and reducing educational levels in children that can go on to perpetuate reduced earnings later in life. Following this, there will be a continuation of a never-ending cycle of poverty between generations to come [32].

Malaysia has been classified as an upper-middle income country in 2008, ahead of other TB endemic countries such as Bangladesh, Myanmar, Indonesia and Sri Lanka [59]. In Malaysia, poverty has seen a diminishing 
trend from $50 \%$ in the 1970 s to $3.6 \%$ in 2008 [28] [50]. Furthermore, the wealth inequality between the metropolitan and rural Malaysians has overall reduced with the year 2009 recording urban and rural poverty at 1.7\% to $8.4 \%$ respectively and in $2014,0.3 \%$ and $1.6 \%$ respectively [21] [66]. The allocated budget dedicated to the National TB programme in the year 2015 came in at around US \$15 million and it was fully funded domestically this year compared to previous years in which Malaysia received minor international funding [20]. The mean monthly household income in 2014 was pegged at RM6141 with a reducing wealth gap in both the rural and urban areas [66]. In view of this data on personal wealth, a retrospective cohort study done in 2008 in Penang calculated that the cost a Malaysian would incur to treat TB would be around US \$916.4 (RM 3796.60) with 80\% constituting treatment of the patient (Chemotherapy, X-rays, tests, transportation, time from work etc) and the remaining to public health services (Healthcare wager, overhead costs, hospital meals etc.) [67].

\subsection{Drug Resistance}

Treatment outcomes have worsened with the emergence of Multi-drug resistance TB (MDR-TB) and a rarer but more deadly pathogen named the Extensive drug resistant TB (XDR-TB) [7] [10] [20]. Globally, there has been little change in resistance trends with an estimated 3.3\% of new TB cases and $20 \%$ of previously treated cases have MDR-TB [7]. Malaysia had case tested 14,701 patients with a total of 319 being laboratory confirmed. Malaysian statistics have demonstrated a low incidence of MDR-TB and XDR-TB [10] [14] [19] [20]. Treatment for these cases often is fraught with side effects, is of a longer duration and is more expensive [16]. In 2015, the global rates of success in treatment of MDR-TB was 50\% but only 43 of the 127 countries had reached the WHO target of $\geq 75 \%$ [7] with Malaysia achieving only 30\% treatment success in 2013 as mentioned earlier. Furthermore, there is a lack of rapid diagnostic test in laboratories outside Klang Valley as only 2 sites are performing the rapid Xpert MTB/RIF to detect MDR-TB [20]. A lack of facilities can lead to delayed treatment for up to 8 weeks until drug susceptibility tests return [6], which is often longer than the patient's average time of survival, especially in HIV co-infection [2].

\subsection{Clinical and Investigational Factors}

Cough (92\%) was the common symptom in Pulmonary TB [68]. Malaysian data shows that $57 \%$ of inpatient drug sensitive TB patients present with prolonged productive cough, night sweats, anorexia, fever and loss of weight, with the remaining having haemoptysis (34\%) and/or dysphagia and diarrhoea (9\%) [22]. Foreigners exhibited a different pattern male foreign workers had cough (91\%), fever $(70 \%)$ and a positive BCG status while females were more likely to have lymphadenopathy (22\%) [22]. A Malaysian retrospective cohort study on 525 patients with TB and HIV Co-infection, the most common form of Tuberculosis was Pulmonary TB. This study also found that cough (88.4\%), loss of appetite and/or weight loss (82.3\%) and fever (73.2\%) were the main clinical presentations in pulmonary TB whereas loss of appetite and/or weight loss (74\%) and fever (61\%) were indicative of extra pulmonary TB [69]. 84\% of TB in HIV patients in Malaysia have atypical clinical and investigational findings. However in TB patients without HIV, it was discovered that lymphadenopathy (46\%) was the most common presentation of extra pulmonary Tuberculosis [70]. The same study also found that the most common abnormal feature on the X-ray for TB and HIV co-infection was old opacities with or without cavitation and the most common extra pulmonary manifestation of TB was Milliary TB followed by lymph node and spine [69]. It was found that $69 \%$ of pulmonary TB patients had findings on an X-ray with $62 \%$ having typical findings and the remaining having atypical findings. A study in Australia discovered that WHO estimates of smear-positive case rate was a strong predictor of rates of TB, especially in the migrant population [40]. This has seemingly supported the long held belief by various studies that smear positive cases prove to be more contagious than smear negative patient of TB [15] [33]. The authors suggested that each smear positive patient can easily infect 2 new people with one of them being infectious and can eventually infect up to 10 people yearly [5] [33]. However, investigations used to routinely to diagnose TB have weaknesses such as smear positivity in only $50 \%$ of active TB cases, long waiting times for cultures and expensive costs for the newer techniques like NAA or the Interferon assays [8].

\subsection{Comorbidities}

\subsubsection{Diabetes}

Numerous studies have documented that diabetes increases the risk of acquiring active TB [71] [72]. Bates et al. 
had discovered that diabetic patients have a 3 to 8 fold risk of developing symptomatic TB compared to controls [71]. Furthermore, diabetics with TB have a $22.2 \%$ treatment failure rate (define as persistence in smear positive post treatment) compared to $6.9 \%$ in non-diabetic patients and a 5 folds increased risk of mortality [71] [73][75]. In Malaysia, a large retrospective cohort study in a few tertiary care centres categorised a few trends; Diabetics with TB were more commonly seen in the Chinese population and if the patients were $>60$ years of age. Following that, poor treatment outcomes in patients with Diabetes were seen in the male gender and relapsed patients [46]. Nissapatorn and Kuppusamy et al. also showed that Diabetics with TB were often male, experienced more resistance to anti-TB medication, and had better treatment outcomes and lower default rates as opposed to non-Diabetics with TB [76]. The same study also claimed that the rate of pulmonary TB in the Diabetics with TB group was 91\% [76]. It also seems that TB infections are more likely to occur in Type 1 diabetes as opposed to type 2 diabetes [77]. Animal studies have demonstrated that the likely mechanism of this causal relationship is in the nature of diabetes weakening the innate and adaptive immune responses, predisposing to a rapid clinical progression of TB [33]. Diabetes is a major predictor for the re-emerging TB epidemic in Malaysia as the country has achieved its expected prevalence for the year 2025 with an overall prevalence of $11.6 \%[78]$.

\subsubsection{HIV}

In 2014, out of the 9.6 million TB cases worldwide, 1.2 million (12\%) of those cases were also HIV-positive patients [7] [79]. The annual risk of reactivation of TB in HIV Co-infected individuals is estimated at $5 \%-10 \%$ [80]. The highest incidence of TB and HIV co-infection at 74\% occurred in the African, higher than the global average percentage of 51\% [7]. In Malaysia, the 2014 number of TB patients with a known HIV status were 21,698 (88\% of TB cases [20]). Conversely, the incidence of HIV-positive TB patients were 1468 cases (7\%) with mortality in 620 case mortalities [7] [19] [20]. Furthermore, statistics show that only 33\% of all TB and HIV co-infected individuals are actually receiving adequate treatment or any treatment at all [7]. In 2014, the Malaysian rate of HIV positive TB patients on anti-retroviral therapy and co-trimoxazole preventive therapy were at $31 \%$ and $7 \%$ respectively [20]. The study discovered that TB is the most common presenting illness in patients with HIV [7] [79] and that individuals afflicted with HIV are 26 to 31 times more certain of developing active TB [7]. A reason for this is that both the TB and HIV infection will speed up the progression of the diseases concurrently, making it very lethal [80].

A Malaysian retrospective study observed that patients with TB and HIV co-infection were more likely to be male, had CD4 counts less than 200 cells $/ \mathrm{mm}^{3}$ and had better treatment outcome but higher default to treatment rate if they had pulmonary TB [69]. The risk of death in this group of patients is twice as high compared to their non HIV counterparts, even when CD 4 counts and ART are taken into account [81] [82]. Patients with CD4 counts less than $<200$ microliter had a higher risk for mortality with a relative risk (RR) of 27.6 (3.5 - 220.8) compared to CD4 counts between 200-499microliter with an RR of 11.5 (1.2 - 109) [82]. Moreover, systematic reviews from 32 eligible studies have demonstrated that that HIV infected patients have a 2 times higher risk of being infected with primary MDR-TB with a prevalence ratio of $2.72(95 \% \mathrm{Cl} 2.03,3.66)$ but not with acquired MDR-TB [81]. Following these observations, it is clear that the HIV epidemic is responsible for worse outcomes of disease in TB epidemics worldwide and therefore is an important predictor of poor treatment outcomes.

\subsubsection{Other Comorbidities}

Another comorbidity in the literature is malnutrition as it impairs immune responses [33]. Patients with TB often have loss of weight and appetite and that can further aggravate malnourishment [1]. According to both the National Health and Nutrition Examination (NHANES-1) and its follow up study called the NHANES-1 Epidemiological Follow-up Study (NHEFS) malnourished individuals reportedly had a 6 to 10 fold risk of acquiring TB [83]. Moreover, side effects of medication are another barrier to adequate completion of treatment. Generally, there is no difference in adverse events between shorter or longer durations of anti-TB regimens [84]. Zhang, Du and Yin et al. discovered that the most common side effect associated from anti-TB chemotherapy were liver injury 9.8\% (95\% CI, 8.5 - 11.1) and gastrointestinal reactions 6.3\% (95\% CI, 5.3 - 7.4) and predictors for developing these adverse events were patient knowledge, smoking status, age and sex [85]. Other known risk factors for adverse drug reactions to anti-TB medication are age $>40$, Obesity, smoking, alcoholism, anemia, higher baseline ALT and AST, MDR-TB medication, HIV co-infection and hepatitis B and C [86]-[88]. A few studies 
found that renal impairment and long term use of steroids lead to more cases of reactivation of TB [89]. Other studies identified that other comorbidities such as COPD, Malignancy and usage of immunosuppressant drugs were associated with TB reactivation or primary TB infection [6] [63] [90].

\section{Conclusion}

The TB epidemic still remains a management challenge in various developing countries. Worse still, some countries like Malaysia are seeing a re-emergence of the TB epidemic especially with increasing number of resistance TB cases and the HIV epidemic. There are multiple factors that can act as predictors of risk of a worse disease outcome in TB. Some of these factors such as demographic risk factors, low socio-economic status, crowding, poor ventilation, poverty, malnourishment, diabetes and HIV have allowed TB to persist. The control of TB in Malaysia is impressive but may not be enough. More research and information need to be ascertained to better target future public health programmes.

\section{Statements of Competing Interests}

None.

\section{References}

[1] Zaman, K. (2010) Tuberculosis: A Global Health Problem. Journal of Health, Population, and Nutrition, $28,111$. http://dx.doi.org/10.3329/jhpn.v28i2.4879

[2] Ducati, R.G., Ruffino-Netto, A., Basso, L.A. and Santos, D.S. (2006) The Resumption of Consumption: A Review on Tuberculosis. Memórias do Instituto Oswaldo Cruz, 101, 697-714. http://dx.doi.org/10.1590/S0074-02762006000700001

[3] Knechel, N.A. (2009) Tuberculosis: Pathophysiology, Clinical Features, and Diagnosis. Critical Care Nurse, 29, 3443. http://dx.doi.org/10.4037/ccn2009968

[4] Glickman, M.S. and Jacobs, W.R. (2001) Microbial Pathogenesis of Mycobacterium tuberculosis: Dawn of a Discipline. Cell, 104, 477-485. http://dx.doi.org/10.1016/S0092-8674(01)00236-7

[5] Maher, D. (2009) The Natural History of Mycobacterium tuberculosis Infection in Adults. Tuberculosis: A Comprehensive Clinical Reference. 129-132. http://dx.doi.org/10.1016/b978-1-4160-3988-4.00013-5

[6] Clinical Practice Guidelines (2012) Management of Tuberculosis. In: Ministry of Health Malaysia AoMMatMTS, Ed., 3rd Edition, Malaysia Health Technology Assessment Section (MaHTAS) of the Medical Development Division, Ministry of Health Malaysia, Putrajaya, 2-5, 80-83.

[7] (2015) Global Tuberculosis Report 2015. World Health Organization.

[8] Lauzardo, M. and Ashkin, D. (2000) Phthisiology at the Dawn of the New Century: A Review of Tuberculosis and the Prospects for Its Elimination. Chest, 117, 1455-1473. http://dx.doi.org/10.1378/chest.117.5.1455

[9] Organization, W.H. (2010) Treatment of Tuberculosis: Guidelines. World Health Organization.

[10] Iyawoo, K. (2004) Tuberculosis in Malaysia: Problems and Prospect of Treatment and Control. Tuberculosis, 84, 4-7. http://dx.doi.org/10.1016/j.tube.2003.08.014

[11] Society, A.T., America IDSo (2003) Treatment of Tuberculosis. MMWR Recommendations and Reports: Morbidity and Mortality Weekly Report Recommendations and Reports/Centers for Disease Control, 52, 1.

[12] (2008) Implementing the WHO Stop TB Strategy: A Handbook for National TB Control Programmes. World Health Organization.

[13] Ortblad, K.F., Salomon, J.A., Bärnighausen, T. and Atun, R. (2015) Stopping Tuberculosis: A Biosocial Model for Sustainable Development. The Lancet, 386, 2354-2362. http://dx.doi.org/10.1016/S0140-6736(15)00324-4

[14] Sistem Maklumat Tibi Kementerian Kesihatan Malaysia (2011) Fakta-Fakta Utama Program Kawalan Tibi. Unpublished Document.

[15] Lin, C.-H., Lin, C.-J., Kuo, Y.-W., Wang, J.-Y., Hsu, C.-L., Chen, J.-M., et al. (2014) Tuberculosis Mortality: Patient Characteristics and Causes. BMC Infectious Diseases, 14, 5. http://dx.doi.org/10.1186/1471-2334-14-5

[16] Nachega, J.B. and Chaisson, R.E. (2003) Tuberculosis Drug Resistance: A Global Threat. Clinical Infectious Diseases, 36, S24-S30. http://dx.doi.org/10.1086/344657

[17] Elmi, O.S., Hasan, H., Abdullah, S., Jeab, M.Z.M., Alwi, Z.B. and Naing, N.N. (2015) Multidrug-Resistant Tuberculosis and Risk Factors Associated with Its Development: A Retrospective Study. The Journal of Infection in Developing 
Countries, 9, 1076-1085. http://dx.doi.org/10.3855/jidc.6162

[18] Davies, P.D. (2000) Tuberculosis: The Global Epidemic. Journal of the Indian Medical Association, 98, $100-102$.

[19] (2014) Country Progress Report. Ministry of Health Malaysia, Philippines.

[20] (2014) Estimates of Tuberculosis and MDR-TB Profile-Malaysia. World Health Organisation.

[21] Jaafar, S., Suhaili, M., Mohd Noh, K., Ehsan, F. and Lee, F. (2010) Malaysia: Primary Health Care Key to Intersectoral Action for Health and Equity. World Health Organization and Public Health Agency of Canada. http://www.who.int/entity/social_determinants/resources/isa_primary_care_mys.pdf

[22] Ibrahim, J. (2010) Tuberculosis: An Eight Year (2000-2007) Retrospective Study at the University of Malaya Medical Centre (UMMC), Kuala Lumpur, Malaysia. The Southeast Asian Journal of Tropical Medicine and Public Health, 41, 378-385.

[23] Nissapatorn, V., Lim, Y., Jamaiah, I., Chin, H.M., Ilyana, M., Nonaziah, M., Hasifah, A.S. and Kuppusamy, I. (2007) Tuberculosis in Malaysia: A Continuing Surge. The Southeast Asian Journal of Tropical Medicine and Public Health, 38, 231-239.

[24] Venugopalan, B. (2004) An Evaluation of the Tuberculosis Control Programme of Selangor State, Malaysia for the Year 2001. The Medical journal of Malaysia, 59, 20-25.

[25] Nantha, S. (2014) A Review of Tuberculosis Research in Malaysia. Medical Journal of Malaysia, 69, 88-102.

[26] Shimao, T. (2005) [Tuberculosis and Its Control—Lessons from the Past and Future Prospect]. Kekkaku: [Tuberculosis], 80, 481-489.

[27] Leong, C. (2006) Pre-Employment Medical Examination of Indonesian Domestic Helpers in a Private Clinic in Johor Bahru-An Eight Year Review. Medical Journal of Malaysia, 61, 592-598.

[28] Organization, W.H. (2008) Health Equity through Intersectoral Action: An Analysis of 18 Country Case Studies. Public Health Agency of Canada.

[29] (2014) Tuberculosis MAftPo Stop TB at the Source. In: Adlan, Y.J.H.Y., Ed., MAPTB Newsletter, Ministry of Health Malaysia.

[30] Dormandy, T. (2000) The White Death: A History of Tuberculosis. New York University Press, New York.

[31] Marmot, M., Friel, S., Bell, R., Houweling, T.A. and Taylor, S., on behalf of the Commission on Social Determinants of Health (2008) Closing the Gap in a Generation: Health Equity through Action on the Social Determinants of Health. The Lancet, 372, 1661-1669. http://dx.doi.org/10.1016/S0140-6736(08)61690-6

[32] Hargreaves, J.R., Boccia, D., Evans, C.A., Adato, M., Petticrew, M. and Porter, J. (2011) The Social Determinants of Tuberculosis: From Evidence to Action. American Journal of Public Health, 101, 654-662. http://dx.doi.org/10.2105/AJPH.2010.199505

[33] Narasimhan, P., Wood, J., MacIntyre, C.R. and Mathai, D. (2013) Risk Factors for Tuberculosis. Pulmonary Medicine, 2013, Article ID: 828939. http://dx.doi.org/10.1155/2013/828939

[34] Orofino, R. de L., Brasil, P.E., Trajman, A., Schmaltz, C.A., Dalcolmo, M. and Rolla, V.C. (2012) Predictors of Tuberculosis Treatment Outcomes. Jornal Brasileiro de Pneumologia, 38, 88-97. http://dx.doi.org/10.1590/S1806-37132012000100013

[35] Dujaili, J.A., Sulaiman, S.A.S., Hassali, M.A., Awaisu, A., Blebil, A.Q. and Bredle, J.M. (2015) Health-Related Quality of Life as a Predictor of Tuberculosis Treatment Outcomes in Iraq. International Journal of Infectious Diseases, 31, 4-8. http://dx.doi.org/10.1016/j.ijid.2014.12.004

[36] Choi, H., Lee, M., Chen, R.Y., Kim, Y., Yoon, S., Joh, J.S., et al. (2014) Predictors of Pulmonary Tuberculosis Treatment Outcomes in South Korea: A Prospective Cohort Study, 2005-2012. BMC Infectious Diseases, 14, 360. http://dx.doi.org/10.1186/1471-2334-14-360

[37] Naidoo, P., Peltzer, K., Louw, J., Matseke, G., Mchunu, G. and Tutshana, B. (2013) Predictors of Tuberculosis (TB) and Antiretroviral (ARV) Medication Non-Adherence in Public Primary Care Patients in South Africa: A Cross Sectional study. BMC Public Health, 13, 396. http://dx.doi.org/10.1186/1471-2458-13-396

[38] Hussain, H., Akhtar, S. and Nanan, D. (2003) Prevalence of and Risk Factors Associated with Mycobacterium tuberculosis Infection in Prisoners, North West Frontier Province, Pakistan. International Journal of Epidemiology, 32, 794-799. http://dx.doi.org/10.1093/ije/dyg247

[39] Ismail, I. and Bulgiba, A. (2013) Predictors of Death during Tuberculosis Treatment in TB/HIV Co-Infected Patients in Malaysia. PLoS ONE, 8, e73250. http://dx.doi.org/10.1371/journal.pone.0073250

[40] Watkins, R.E. and Plant, A.J. (2002) Predicting Tuberculosis among Migrant Groups. Epidemiology and Infection, 129, 623-628. http://dx.doi.org/10.1017/S0950268802007604

[41] Marais, B.J., Gie, R.P., Schaaf, H.S., Hesseling, A.C., Obihara, C.C., Nelson, L.J., et al. (2004) The Clinical Epidemi- 
ology of Childhood Pulmonary Tuberculosis: A Critical Review of Literature from the Pre-Chemotherapy Era. The International Journal of Tuberculosis and Lung Disease, 8, 278-285.

[42] Tocque, K., Regan, M., Remmington, T., Beeching, N., Jamieson, I., Syed, Q. and Davies, P.D. (1999) Social Factors Associated with Increases in Tuberculosis Notifications. European Respiratory Journal, 13, 541-545. http://dx.doi.org/10.1183/09031936.99.13354199

[43] Diwan, V.K. and Thorson, A. (1999) Sex, Gender, and Tuberculosis. The Lancet, 353, 1000-1001. http://dx.doi.org/10.1016/S0140-6736(99)01318-5

[44] Diwan, V., Thorson, A. and Winkvist, A. (1998) Gender and Tuberculosis: An International Workshop. Report from an International Research Workshop at the Nordic School of Public Health, Nordic School of Public Health, Göteborg, 24-26 May 1998.

[45] Coussens, A.K., Wilkinson, R.J., Nikolayevskyy, V., Elkington, P.T., Hanifa, Y., Islam, K., et al. (2013) Ethnic Variation in Inflammatory Profile in Tuberculosis. PLoS Pathogens, 9, e1003468. http://dx.doi.org/10.1371/journal.ppat.1003468

[46] Sulaiman, S.A., Khan, A.H., Muttalif, A.R., Hassali, M.A., Ahmad, N. and Iqubal, M.S. (2013) Impact of Diabetes Mellitus on Treatment Outcomes of Tuberculosis Patients in Tertiary Care Setup. The American Journal of the Medical Sciences, 345, 321-325. http://dx.doi.org/10.1097/MAJ.0b013e318288f8f3

[47] (2015) Migration and Tuberculosis: A Pressing Issue. In: Division, M.H., Ed., International Organization for Migration.

[48] Mondal, M.N.I., Nazrul, H.M., Chowdhury, M.R.K. and Howard, J. (2014) Socio-Demographic Factors Affecting Knowledge Level of Tuberculosis Patients in Rajshahi City, Bangladesh. African Health Sciences, 14, 855-865.

[49] Shetty, N., Shemko, M. and Abbas, A. (2004) Knowledge, Attitudes and Practices Regarding Tuberculosis among Immigrants of Somalian Ethnic Origin in London: A Cross-Sectional Study. Communicable Disease and Public Health/PHLS, 7, 77-82.

[50] Noh, K. and Jaafar, S., Eds. (2011) Health in All Policies: The Primary Health Care Approach in Malaysia. 50-Years Experience in Addressing Social Determinants of Health through Intersectoral Action for Health. Draft Background Paper, World Conference on Social Determinants of Health, Rio de Janeiro, 19-21 October 2011.

[51] Mokhtar, K.S., Rahman, N., Shariff, N. and Nor, W.A.W.M. (2012) Tuberculosis in Malaysia: A Study on the Level of Societal Awareness and Stigma. IOSR Journal of Humanities and Social Science, 1, 59-64. http://dx.doi.org/10.9790/0837-0145964

[52] Lönnroth, K., Jaramillo, E., Williams, B.G., Dye, C. and Raviglione, M. (2009) Drivers of Tuberculosis Epidemics: The Role of Risk Factors and Social Determinants. Social Science \& Medicine, 68, 2240-2246. http://dx.doi.org/10.1016/j.socscimed.2009.03.041

[53] Nava-Aguilera, E., Andersson, N., Harris, E., Mitchell, S., Hamel, C., Shea, B., et al. (2009) Risk Factors Associated with Recent Transmission of Tuberculosis: Systematic Review and Meta-Analysis. The International Journal of Tuberculosis and Lung Disease, 13, 17-26.

[54] Lee, M., Leung, C., Kam, K., Wong, M., Leung, M., Tam, C., et al. (2008) Early and Late Tuberculosis Risks among Close Contacts in Hong Kong. The International Journal of Tuberculosis and Lung Disease, 12, 281-287.

[55] Al-Darraji, H.A.A., Kamarulzaman, A. and Altice, F.L. (2014) Latent Tuberculosis Infection in a Malaysian Prison: Implications for a Comprehensive Integrated Control Program in Prisons. BMC Public Health, 14, 22. http://dx.doi.org/10.1186/1471-2458-14-22

[56] O’Boyle, S., Power, J., Ibrahim, M. and Watson, J. (2002) Factors Affecting Patient Compliance with Anti-Tuberculosis Chemotherapy Using the Directly Observed Treatment, Short-Course Strategy (DOTS). The International Journal of Tuberculosis and Lung Disease, 6, 307-312.

[57] Lienhardt, C., Fielding, K., Sillah, J., Tunkara, A., Donkor, S., Manneh, K., et al. (2003) Risk Factors for Tuberculosis Infection in Sub-Saharan Africa: A Contact Study in the Gambia. American Journal of Respiratory and Critical Care Medicine, 168, 448-455. http://dx.doi.org/10.1164/rccm.200212-1483OC

[58] Morrison, J., Pai, M. and Hopewell, P.C. (2008) Tuberculosis and Latent Tuberculosis Infection in Close Contacts of People with Pulmonary Tuberculosis in Low-Income and Middle-Income Countries: A Systematic Review and Meta-Analysis. The Lancet Infectious Diseases, 8, 359-368. http://dx.doi.org/10.1016/S1473-3099(08)70071-9

[59] Asia WHO-WPS-E (2008) Health in Asia and the Pacific. World Health Organisation, 51 p.

[60] Bates, M.N., Khalakdina, A., Pai, M., Chang, L., Lessa, F. and Smith, K.R. (2007) Risk of Tuberculosis from Exposure to Tobacco Smoke: A Systematic Review and Meta-Analysis. Archives of Internal Medicine, 167, 335-342. http://dx.doi.org/10.1001/archinte.167.4.335

[61] Arcavi, L. and Benowitz, N.L. (2004) Cigarette Smoking and Infection. Archives of Internal Medicine, 164, $2206-2216$. 
http://dx.doi.org/10.1001/archinte.164.20.2206

[62] Lönnroth, K., Williams, B.G., Stadlin, S., Jaramillo, E. and Dye, C. (2008) Alcohol Use as a Risk Factor for Tuberculosis-A Systematic Review. BMC Public Health, 8, 289. http://dx.doi.org/10.1186/1471-2458-8-289

[63] Moran-Mendoza, O., Marion, S., Elwood, K., Patrick, D. and FitzGerald, J. (2010) Risk Factors for Developing Tuberculosis: A 12-Year Follow-Up of Contacts of Tuberculosis Cases. The International Journal of Tuberculosis and Lung Disease, 14, 1112-1119.

[64] Al-Darraji, H.A., Wong, K.C., Yeow, D.G., Fu, J.J., Loeliger, K., Paiji, C., et al. (2014) Tuberculosis Screening in a Novel Substance Abuse Treatment Center in Malaysia: Implications for a Comprehensive Approach for Integrated Care. Journal of Substance Abuse Treatment, 46, 144-149. http://dx.doi.org/10.1016/j.jsat.2013.08.023

[65] Phelps, G. and Crabtree, S. (2013) Worldwide, Median Household Income About \$10,000. The Gallup Organization.

[66] Department of Statistics (2015) Report of Household Income and Basic Amenities Survey 2014. Household Income \& Expenditure.

[67] Elamin, E.I., Ibrahim, M.I., Sulaiman, S.A. and Muttalif, A.R. (2008) Cost of Illness of Tuberculosis in Penang, Malaysia. Pharmacy World \& Science: PWS, 30, 281-286. http://dx.doi.org/10.1007/s11096-007-9185-0

[68] Abdul Razak, M. (2004) Significance of Symptoms and Investigations in Tubeculosis Case Finding. Journal of Pharmaceutical Sciences, 2, 29-30.

[69] Nissapatorn, V., Kuppusamy, I., Sim, B., Quek, K.F. and Khairul Anuar, A. (2005) Tuberculosis in HIV/AIDS Patients: A Malaysian Experience. The Southeast Asian Journal of Tropical Medicine and Public Health, 36, 946-953.

[70] Nissapatorn, V., Kuppusamy, I., Rohela, M., Anuar, A.K. and Fong, M. (2004) Extrapulmonary Tuberculosis in Peninsular Malaysia: Retrospective Study of 195 Cases. The Southeast Asian Journal of Tropical Medicine and Public Health, 35, 39-45.

[71] Bates, M., Marais, B.J. and Zumla, A. (2015) Tuberculosis Comorbidity with Communicable and Noncommunicable Diseases. Cold Spring Harbor Perspectives in Medicine, 5, a017889. http://dx.doi.org/10.1101/cshperspect.a017889

[72] Syed Suleiman, S.A., Ishaq Aweis, D.M., Mohamed, A.J., RazakMuttalif, A. and Moussa, M.A. (2012) Role of Diabetes in the Prognosis and Therapeutic Outcome of Tuberculosis. International Journal of Endocrinology, 2012, Article ID: 645362. http://dx.doi.org/10.1155/2012/645362

[73] Alisjahbana, B., Sahiratmadja, E., Nelwan, E.J., Purwa, A.M., Ahmad, Y., Ottenhoff, T.H., et al. (2007) The Effect of Type 2 Diabetes Mellitus on the Presentation and Treatment Response of Pulmonary Tuberculosis. Clinical Infectious Diseases, 45, 428-435. http://dx.doi.org/10.1086/519841

[74] Jeon, C.Y. and Murray, M.B. (2008) Diabetes Mellitus Increases the Risk of Active Tuberculosis: A Systematic Review of 13 Observational Studies. PLoS Medicine, 5, e152. http://dx.doi.org/10.1371/journal.pmed.0050152

[75] Baker, M.A., Harries, A.D., Jeon, C.Y., Hart, J.E., Kapur, A., Lönnroth, K., et al. (2011) The Impact of Diabetes on Tuberculosis Treatment Outcomes: A Systematic Review. BMC Medicine, 9, 81. http://dx.doi.org/10.1186/1741-7015-9-81

[76] Nissapatorn, V., Kuppusamy, I., Jamaiah, I., Fong, M., Rohela, M. and Anuar, A.K. (2005) Tuberculosis in Diabetic Patients: A Clinical Perspective. The Southeast Asian Journal of Tropical Medicine and Public Health, 36, 213-220.

[77] Leung, C.C., Lam, T.H., Chan, W.M., Yew, W.W., Ho, K.S., Leung, G.M., et al. (2008) Diabetic Control and Risk of Tuberculosis: A Cohort Study. American Journal of Epidemiology, 167, 1486-1494. http://dx.doi.org/10.1093/aje/kwn075

[78] Letchuman, G., Wan Nazaimoon, W., Wan Mohamad, W., Chandran, L., Tee, G., Jamaiyah, H., et al. (2010) Prevalence of Diabetes in the Malaysian National Health Morbidity Survey III 2006. Medical Journal of Malaysia, 65, 180-186.

[79] Getahun, H., Gunneberg, C., Granich, R. and Nunn, P. (2010) HIV Infection-Associated Tuberculosis: The Epidemiology and the Response. Clinical Infectious Diseases, 50, S201-S207. http://dx.doi.org/10.1086/651492

[80] Mayer, K.H. and Hamilton, C.D. (2010) Synergistic Pandemics: Confronting the Global HIV and Tuberculosis Epidemics. Clinical Infectious Diseases, 50, S67-S70. http://dx.doi.org/10.1086/651475

[81] Suchindran, S., Brouwer, E.S. and Van Rie, A. (2009) Is HIV Infection a Risk Factor for Multi-Drug Resistant Tuberculosis? A Systematic Review. PLoS ONE, 4, e5561. http://dx.doi.org/10.1371/journal.pone.0005561

[82] Ackah, A.N., Digbeu, H., Daillo, K., Greenberg, A.E., Coulibaly, D., Coulibaly, I.M., et al. (1995) Response to Treatment, Mortality, and CD4 Lymphocyte Counts in HIV-Infected Persons with Tuberculosis in Abidjan, Côte d'Ivoire. The Lancet, 345, 607-610. http://dx.doi.org/10.1016/S0140-6736(95)90519-7

[83] Cegielski, J., Kohlmeier, L., Cornoni-Huntley, J., Eds. (1995) Malnutrition and Tuberculosis in a Nationally Representative Cohort of Adults in the United States, 1971-1987. Proceedings of the 44th Annual Meeting, American Society of Tropical Medicine and Hygiene, American Society of Tropical Medicine and Hygiene, San Antonio. 
[84] Gelband, H. (1999) Regimens of Less than Six Months for Treating Tuberculosis. Cochrane Database of Systematic Reviews, No. 4, Article No. CD001362. http://dx.doi.org/10.1002/14651858.cd001362

[85] Zhang, T., Du, J., Yin, X., Xue, F., Liu, Y., Li, R., et al. (2015) Adverse Events in Treating Smear-Positive Tuberculosis Patients in China. International Journal of Environmental Research and Public Health, 13, 86. http://dx.doi.org/10.3390/ijerph13010086

[86] Chung-Delgado, K., Revilla-Montag, A., Guillen-Bravo, S., Velez-Segovia, E., Soria-Montoya, A., Nuñez-Garbin, A., et al. (2011) Factors Associated with Anti-Tuberculosis Medication Adverse Effects: A Case-Control Study in Lima, Peru. PLoS ONE, 6, e27610. http://dx.doi.org/10.1371/journal.pone.0027610

[87] Vilariça, A.S., Diogo, N., André, M. and Pina, J. (2009) Adverse Reactions to Antituberculosis Drugs in In-Hospital Patients: Severity and Risk Factors. Revista Portuguesa de Pneumologia, 16, 431-451. http://dx.doi.org/10.1016/S0873-2159(15)30040-4

[88] Khalili, H., Dashti-Khavidaki, S., Rasoolinejad, M., Rezaie, L. and Etminani, M. (2015) Anti-Tuberculosis Drugs Related Hepatotoxicity, Incidence, Risk Factors, Pattern of Changes in Liver Enzymes and Outcome. DARU Journal of Pharmaceutical Sciences, 17, 163-167.

[89] Nantha, Y.S. (2012) Influence of Diabetes Mellitus and Risk Factors in Activating Latent Tuberculosis Infection: A Case for Targeted Screening in Malaysia. Medical Journal of Malaysia, 67, 467-472.

[90] Inghammar, M., Ekbom, A., Engström, G., Ljungberg, B., Romanus, V., Löfdahl, C.-G. and Egesten, A. (2010) COPD and the Risk of Tuberculosis-A Population-Based Cohort Study. PLoS ONE, 5, e10138.

http://dx.doi.org/10.1371/journal.pone.0010138 


\section{List of Abbreviations}

TB: Tuberculosis

TST: Tuberculin Skin Test

NAA: Nucleic Acid Amplification

PCR: Polymerase Chain Reaction

FDC: Fixed Dose Combination

HRZE: Isoniazid (H), Rifampicin (R), Pyrazinamide (Z), Ethambutol (E)

WHO: World Health Organisation

MDR-TB: Multi-Drug Resistant TB

XDR-TB: Extensively-Drug Resistant TB

BCG Vaccine: Bacille Calmette Guerin Vaccine

DOTS: Directly Observed Therapy Short Course

CSDH: The Commission on Social Determinants of Health

FACIT-TB: Functional Assessment of Chronic Illness Therapy-TB

RR: Relative Risk

ARR: Adjusted Risk Ratio

NEP: New Economic Policy

AFB: Acid Fast Bacilli

CD4: Cluster Differentiation 4

\section{Appendix}

Table A1. Definitions and classifications_adapted from Malaysian Clinical Practice Guidelines 2012(6).

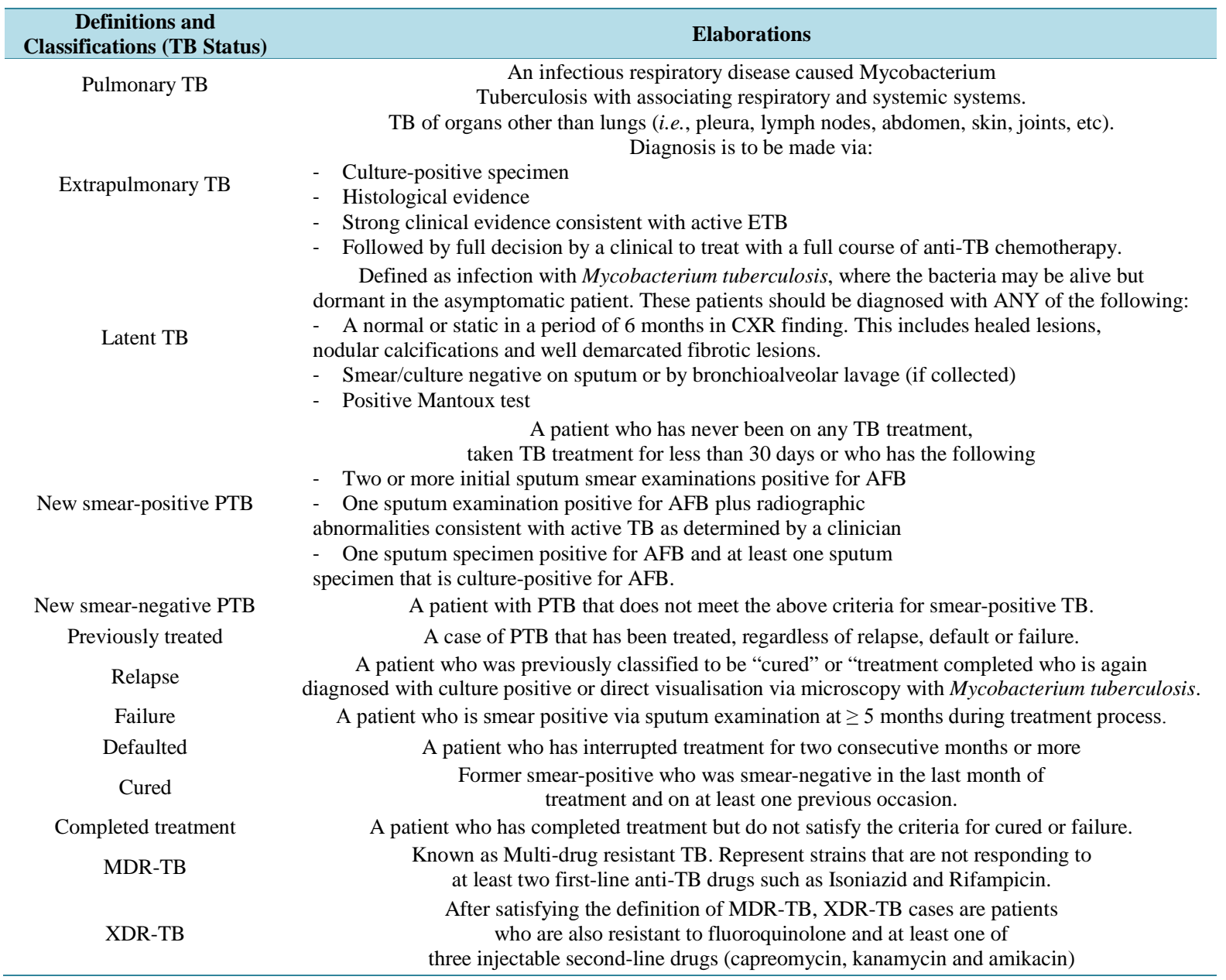

